\title{
HUBUNGAN AKTIVITAS FISIK DENGAN NYERI HAID (DISMENOREA) PADA SANTRIWATI MADRASAH ALIYAH SWASTA ULUMUDDIN UTEUNKOT CUNDA KOTA LHOKSEUMAWE
}

\author{
Khairunnisa $^{1 *}$, Nora Maulina ${ }^{2}$ \\ ${ }^{1}$ Program Studi Kedokteran Fakultas Kedokteran Universitas Malikussaleh \\ ${ }^{2}$ Bagian Fisiologi Fakultas Kedokteran Universitas Malikussaleh \\ Corresponding author : khairunnisa@yahoo.com
}

\begin{abstract}
Abstrak
Dismenorea masih menjadi keluhan bagi para remaja karena rasa tidak enak dan tidak nyaman pada perut bagian bawah yang dapat mengganggu aktivitas sehari-hari. Dismenorea pada usia remaja sangat dipengaruhi oleh aktivitas fisik, remaja yang aktif dalam melakukan beragam aktivitas fisik akan menurunkan terjadinya dismenorea. Tujuan penelitian ini adalah untuk mendeskripsikan dan menganalisis hubungan aktivitas fisik dengan nyeri haid pada santriwati Madrasah Aliyah Swasta Ulumuddin Uteunkot-Cunda Kota Lhokseumawe tahun 2016. Rancangan penelitian cross-sectional dengan sampelsebanyak 74 orang dan subjek penelitian diminta untuk mengisi kuesioner. Data dianalisis dengan uji chi-square dengan nilai $(\alpha=0,05)$. Penelitian ini menunjukkan bahwa 40,5\% santriwati memiliki aktivitas fisik berat dan $82,4 \%$ santriwati mengalami nyeri haid ringan. Analisis bivariat menunjukkan tidak ada hubungan aktivitas fisik dengan nyeri haid $(\mathrm{p}=0,238)$.
\end{abstract}

Kata kunci: aktivitas fisik, nyeri haid

\section{THE CORRELATION BETWEEN PHYSICAL ACTIVITY WITH PAINFUL OF MENSTRUATION IN FEMALE STUDENTS OF ULUMUDDIN ISLAMIC}

\begin{abstract}
Boarding School Uteunkot-Cunda Lhokseumawe on 2016 Dysmenorrhoea remains a major complaint among female teenagers because malaise and discomfort in the lower abdomen can interfere daily activities. Dysmenorrhoea in adolescent age is influenced by physical activity. Teenagers who are active in a variety of physical activity experience less dysmenorrhoea. The purpose of this research is to describe and analyze the correlation of the physical activity painful of menstruation in female students of Ulumuddin Islamic Boarding School Uteunkot-Cunda Lhokseumawe on 2016. The design of this research was cross-sectional with a sample of 74 female students and the research subjects were asked to fill out a questionnaire. Data was analyzed by chi-square test with a value $(\alpha=0,05)$. The finding of the research showed $40,5 \%$ of female student at the school were involved in heavy physical activity and $82,4 \%$ of them experienced mild menstrual pain. The bivariate analysis show there was no correlation between physical activity and menstrualpain $(\mathrm{p}=0,238)$.
\end{abstract}

Keywords: physical activity, menstrual pain 


\section{PENDAHULUAN}

Dismenorea atau nyeri haid adalah nyeri yang dirasakan sebelum atau saat menstruasi yang disebabkan oleh kejang otot uterus. ${ }^{1}$ Sakit yang menusuk, nyeri yang hebat disekitar bagian bawah perut dan bahkan kadang mengalami kesulitan berjalan ketika haid menyerang. ${ }^{2}$ Nyeri haid merupakan masalah umum yang sering dikeluhkan oleh wanita yang mengalami menstruasi. ${ }^{3}$ Hampir semua perempuan mengalami rasa tidak enak di perut bawah sebelum dan selama haid disertai rasa mual, sehingga penderita tidak dapat melakukan aktivitas sehari-harinya dan memerlukan waktu untuk beristirahat. Nyeri yang terasa dibagian bawah perut biasanya terjadi di hari pertama sampai kedua setelah pengeluaran darah. Derajat nyeri berkurang setelah pengeluaran darah yang sangat banyak. ${ }^{4}$ Nyeri haid bukanlah penyakit melainkan gejala yang timbul akibat adanya kelainan pada organ panggul. Remaja wanita yang mengalami dismenorea paling sering terjadi pada usia 14-19 tahun. Remaja wanita yang tinggal di pondok pesantren setiap hari harus menjalani rutinitas yang padat dan serba apa adanya yang menuntut mereka untuk dapat agar lebih mandiri. Tingkat kemandirian mempengaruhi tingkat aktivitas fisik yang beragam mulai dari aktivitas fisik ringan, sedang, sampai berat. Selain tingkat kemandirian, fasilitas olahraga yang dapat mereka gunakan dengan leluasa juga dapat meningkatkan aktivitas fisik para santriwati. Berdasarkan data yang diperoleh, Madrasah Aliyah Swasta Ulumuddin Uteunkot-Cunda Kota Lhokseumawe memiliki jumlah santri yang lebih banyak dibandingkan dengan Madrasah Aliyah Swasta lainnya yang ada di Kota Lhokseumawe

\section{METODE PENELITIAN}

\section{Desain penelitian}

Penelitian ini menggunakan jenis penelitian deskriptif analitik dengan rancangan penelitian cross sectional. Lokasi yang dipilih untuk penelitian ini adalah Dayah Ulumuddin UteunkotCunda Kota Lhokseumawe

\section{Populasi dan sampel penelitian}

Populasi dalam penelitian ini adalah semua santriwati Madrasah Aliyah Swasta Ulumuddin Uteunkot-Cunda Kota Lhokseumawe yang berjumlah 318 orang. Sampel dalam penelitian ini adalah santriwati Madrasah Aliyah Swasta Ulumuddin Uteunkot-Cunda Kota Lhokseumawe yang memenuhi kriteria inklusi dan eksklusi. 
Kriteria Inklusi :

1. Santriwati Madrasah Aliyah Swasta Ulumuddin Uteunkot-Cunda Kota

2. Lhokseumawe yang berusia 14- 19 tahun

3. Santriwati yang sudah mengalami menstruasi.

4. Santriwati yang memiliki siklus menstruasi normal.

5. Santriwati yang bersedia menjadi responden.

Kriteria Eksklusi :

1. Santriwati yang telah terdiagnosis mengalami gangguan reproduksi

(dismenorea sekunder misal : endometriosis, penyakit radang panggul dan kista coklat).

2. Santriwati yang tidak hadir pada saat dilakukan penelitian.

\section{Teknik pengambilan sampel}

Sampel pada penelitian ini diambil dengan cara proportional sampling.Penentuan jumlah sampel pada setiap kelas dengan cara Random Sampling berdasarkan teknik proportional sampling. Adapun rumus dalam teknik proportional sampling adalah sebagai berikut

$$
\mathrm{n}=\frac{\sum \text { Jumlah santriwati kelas }}{\sum \text { Total santriwati }} \text {, sampel }
$$

Berdasarkan hasil perhitungan maka sampel dari tiap kelas dapat dilihat pada tabel dibawah ini

Tabel 4.1 Jumlah Santriwati MAS Ulumuddin Uteunkot-Cunda Kota Lhokseumawe tahun 2016

\begin{tabular}{clcc}
\hline No & Kelas & Jumlah Santriwati & Jumlah Sampel \\
\hline 1 & X-C & 28 & 6 \\
2 & X-D & 28 & 6 \\
3 & X-E & 29 & 6 \\
4 & X-F & 29 & 7 \\
5 & XI-C & 37 & 8 \\
6 & XI-D & 37 & 8 \\
7 & XI-E & 38 & 8 \\
8 & XII-C & 31 & 8 \\
9 & XII-D & 31 & 8 \\
10 & XII-E & 31 & 9 \\
\hline \multicolumn{2}{c}{ Jumlah } & 318 & $\mathbf{7 4}$ \\
\hline
\end{tabular}




\section{Analisis Data}

Analisis dan penyajian data yang dilakukan adalah sebagai berikut:

1. Analisis Univariat

Analisis univariat adalah analisis dalam bentuk tabel distribusi frekuensi untuk melihat gambaran intensitas nyeri dan aktivitas fisik pada santriwati Madrasah Aliyah Swasta Ulumuddin Uteunkot-Cunda kota Lhokseumawe tahun 2016.

\section{Analisis Bivariat}

Analisis bivariat dalam penelitian ini bertujuan untuk mengetahui hubungan antara aktivitas fisik dan dismenorea pada santriwati Madrasah Aliyah Swasta Ulumuddin Uteunkot-Cunda kota Lhokseumawe tahun 2016. Dalam penelitian ini aktivitas fisik merupakan variabel bebas dan kejadian dismenorea merupakan variabel terikat. Analisis bivariat dilakukan dengan menggunakan uji chi square (X2) dengan menggunakan $\alpha=0,05$, derajat kepercayaan $95 \%$ dan $p$ $<0,05$

\section{HASIL PENELITIAN}

\section{Tingkat Aktivitas Fisik}

Hasil penelitian terhadap 74 responden pada santriwati kelas X-XII di MAS Ulumuddin Uteunkot-Cunda Kota Lhokseumawe tahun 2016 dengan kuesioner yang langsung diisi oleh responden didapatkan hasil yang ditunjukkan pada tabel 5.1.

Tabel 5.1 Distribusi frekuensi tingkat aktivitas fisik pada santriwati MAS Ulumuddin Uteunkot-Cunda Kota Lhokseumawe tahun 2016

\begin{tabular}{lcc}
\hline Tingkat Aktivitas Fisik & Frekuensi & Persentase $(\%)$ \\
\hline Aktivitas Fisik Ringan & 28 & 37,8 \\
Aktivitas Fisik Sedang & 16 & 21,6 \\
Aktivitas Fisik Berat & 30 & 40,5 \\
\hline Total & 74 & 100,0 \\
\hline
\end{tabular}

(Sumber: Data primer, 2016)

Tabel diatas menunjukkan frekuensi terendah adalah santriwati dengan aktivitas fisik sedang berjumlah 16 orang $(21,6 \%)$, dan frekuensi tertinggi adalah santriwati dengan aktivitas fisik berat berjumlah 30 orang $(40,5 \%)$.

\section{Derajat Nyeri Haid (Dismenorea)}


Hasil penelitian yang dilakukan pada santriwati MAS Ulumuddin Uteunkot-Cunda Kota

Lhokseumawe tahun 2016 didapatkan hasil

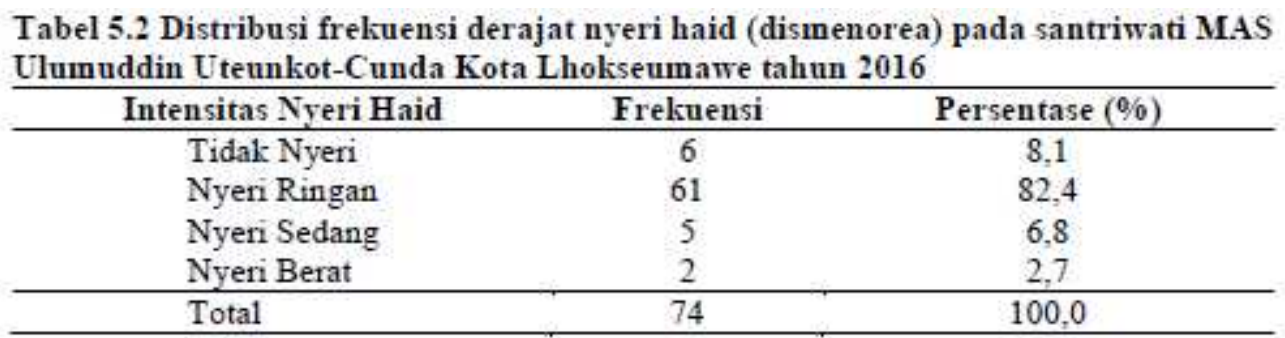

(Sumber: Data primer, 2016)

Tabel diatas menunjukkan frekuensi terendah adalah santriwati yang mengalami nyeri ringan yaitu 61 orang $(82,4 \%)$ dan frekuensi tertinggi santriwati dengan nyeri berat sebanyak 2 orang $(2,7 \%)$.

\section{Hubungan Aktivitas Fisik dengan Nyeri Haid (Dismenorea) pada Santriwati MAS}

\section{Ulumuddin Uteunkot-Cunda Kota Lhokseumawe tahun 2016}

Hasil penelitian yang dilakukan pada 74 responden santriwati MAS Ulumuddin Uteunkot-Cunda Kota Lhokseumawe tahun 2016 didapatkan

Tabel 5.3 Hubungan aktivitas fisik dengan nyeri haid (dismenorea) pada santriwati MAS Ulumuddin Uteunkot-Cunda Kota Lhokseumawe tahun 2016

\begin{tabular}{|c|c|c|c|c|c|c|c|c|c|c|c|}
\hline \multirow{3}{*}{$\begin{array}{l}\text { Aktivitas } \\
\text { Fisik }\end{array}$} & \multicolumn{8}{|c|}{ Derajat Nyeri Haid } & \multirow{2}{*}{\multicolumn{2}{|c|}{ Total }} & \multirow{3}{*}{ p-value } \\
\hline & \multicolumn{2}{|c|}{$\begin{array}{l}\text { Tidak } \\
\text { Nyeri }\end{array}$} & \multicolumn{2}{|c|}{ Ringan } & \multicolumn{2}{|c|}{ Sedang } & \multicolumn{2}{|c|}{ Berat } & & & \\
\hline & $\mathrm{n}$ & $\%$ & $\mathrm{n}$ & $\%$ & $\mathrm{n}$ & $\%$ & $\mathrm{n}$ & $\%$ & $\mathrm{n}$ & $\%$ & \\
\hline Ringan & 3 & 10,7 & 21 & 75 & 4 & 14,3 & 0 & 0 & 28 & 100 & \\
\hline Sedang & 1 & 6,2 & 14 & 87,5 & 1 & 6,2 & 0 & 0 & 16 & 100 & 0,238 \\
\hline Berat & 2 & 6,7 & 26 & 86,7 & 0 & 0 & 2 & 6,7 & 30 & 100 & \\
\hline Total & 6 & 8,1 & 61 & 82,4 & 5 & 6,8 & 2 & 2,7 & 74 & 100 & \\
\hline
\end{tabular}

Dapat dilihat bahwa dari 28 santriwati yang memiliki aktivitas fisik ringan, paling banyak mengalami nyeri haid ringan sebanyak 21orang (75\%), diikuti nyeri haid sedang berjumlah 4 orang $(14,3 \%)$, tidak nyeri berjumlah 3 orang $(10,7 \%)$ dan tidak ditemukan adanya nyeri haid berat. Santriwati yang memiliki aktivitas fisik sedang sebanyak 16 orang, mayoritas mengalami nyeri haid ringan sebanyak 14 orang $(87,5 \%)$, diikuti dengan yang tidak mengalami nyeri haid dan nyeri haid sedang sebanyak 1 orang $(6,2 \%)$, serta tidak ditemukan adanya nyeri haid berat. Kemudian santriwati yang memiliki aktivitas fisik berat berjumlah 30 orang, mayoritas 
mengalami nyeri haid ringan sebanyak 26 orang $(86,7 \%)$, diikuti 2 orang $(6,7 \%)$ yang tidak mengalami nyeri haid nyeri haid berat, serta tidak ditemukan adanya santriwati yang mengalami nyeri haid sedang. Hasil uji statistik menggunakan chi-square didapatkan nilai pvalue sebesar 0,238 $(p>\alpha=0,05)$. Hal ini menunjukkan $\mathrm{H}_{0}$ diterima sehingga tidak ada hubungan antara aktivitas fisik dengan nyeri haid (dismenorea) pada santriwati Madrasah Aliyah Swasta Ulumuddin Uteunkot-Cunda Kota Lhokseumawe tahun 2016.

\section{PEMBAHASAN}

\section{Gambaran distribusi tingkat aktivitas fisik}

Berdasarkan hasil penelitian pada 74 santriwati MAS Ulumuddin Uteunkot-Cunda Kota Lhokseumawe tahun 2016 menunjukkan sebagian besar memiliki aktivitas fisik berat sebanyak 40,5\% karena frekuensi olahraga yang sering dilakukan seperti kegiatan olahraga di madrasah, kegiatan ekstrakurikuler, dan sebagian santriwati juga melakukan olahraga untuk mengisi waktu luang pada sore hari di asrama. Kehidupan santriwati juga menuntut mereka untuk hidup lebih mandiri, dimana selain belajar mereka juga melakukan pekerjaan rumah sendiri seperti menyuci pakaian, menyetrika pakaian, membersihkan tempat tidur sendiri. Kegiatan-kegiatan tersebut dapat meningkatan frekuensi aktivitas fisik para santriwati. Hal ini sejalan dengan penelitian yang dilakukan pada siswi SMPN 2 Demak, yang menunjukkan bahwa sekitar 46 responden $(55,4 \%)$ melakukan kebiasaan olahraga baik. ${ }^{5}$

\section{Gambaran distribusi derajat nyeri haid (Dismenorea).}

Berdasarkan hasil penelitian didapatkan bahwa derajat nyeri haid (dismenorea) pada 74 santriwati MAS lumuddin Uteunkot-Cunda Kota Lhokseumawe tahun 2016 menunjukkan sebagian besar mengalami nyeri haid ringan $(82,4 \%)$. Hal ini dapat disebabkan karena intensitas nyeri pada individu berbeda dipengaruhi oleh deskripsi individu tentang nyeri, persepsi dan pengalaman nyeri. Nyeri dismenorea terjadi karena ada peningkatan kadar prostaglandin. Peningkatan ini akan mengakibatkan kontraksi uterus dan vasokontriksi pembuluh darah maka aliran darah yang menuju ke uterus menurun sehingga uterus tidak mendapatkan suplai oksigen yang adekuat sehingga menyebabkan nyeri. ${ }^{6}$ Menurut Clitheroe dan Pickles, endometrium dalam fase sekresi memproduksi prostaglandin F2 sehingga menyebabkan kontraksi otot-otot polos. Jika kadar prostaglandin yang berlebihan memasuki peredaran darah, maka selain dismenore 
dapat juga dijumpai efek lainnya seperti: mual, muntah, diare. Jelaslah bahwa peningkatan kadar prostaglandin memegang peranan penting pada timbulnya dismenorea primer. ${ }^{7}$ Dapat juga disebabkan oleh tingkat aktivitas fisik berat. Olahraga termasuk kedalam aktivitas fisik berat, kebiasaan olahraga yang rutin dapat meningkatkan sirkulasi darah dan kadar oksigen sehingga aliran darah dan oksigen menuju uterus menjadi lancar dan mengurangi rasa nyeri ketika menstruasi. Hal ini sejalan dengan penelitian sebelumnya yang dilakukan di India, pada penelitian tersebut didapatkan 51 responden (47,6\%) mengalami nyeri ringan, 24 responden $(22,4 \%)$ mengalami nyeri sedang, dan 4 responden $(3,7 \%)$ mengalami nyeri berat. ${ }^{7}$ Penelitian ini berbeda dengan penelitian yang dilakukan pada 80 siswi SMA Negeri 5 Banda Aceh, dimana hasil penelitian menunjukkan $44(55 \%)$ siswi mengalami nyeri haid berat, 27 (33,8\%) siswi mengalami nyeri haid sedang, dan $9(11,3 \%)$ mengalami nyeri haid ringan. ${ }^{8}$

\section{Hubungan Aktivitas Fisik dengan Nyeri Haid (Dismenorea) pada Santriwati MAS Ulumuddin Uteunkot-Cunda Kota Lhokseumawe tahun 2016}

Data yang diperoleh dari hasil uji statistik menunjukkan bahwa tidak terdapat hubungan aktivitas fisik dengan nyeri haid (dismenorea) pada santriwati MAS Ulumuddin Uteunkot-Cunda Kota Lhokseumawe tahun 2016. Hasil penelitian ini memberikan gambaran bahwa setiap orang memberikan reaksi yang berbeda-beda terhadap nyeri haid. Hal ini disebabkan karena nyeri haid tidak hanya dipengaruhi oleh aktivitas fisik tapi dapat disebabkan oleh persepsi setiap individu terhadap nyeri yang bersifat subjektif sehingga dapat mempengaruhi respon nyeri yang bervariasi. Nyeri haid (dismenorea) juga dapat disebabkan oleh beberapa faktor seperti status

gizi, aliran menstruasi yang hebat, riwayat keturunan stres dan ketidak seimbangan hormon, ${ }^{8}$ namun faktorfaktor tersebut tidak diteliti oleh peneliti dalam penelitian ini. Faktor hormonal setiap individu berbeda-beda sehingga efek yang ditimbulkan juga berbeda. Status gizi juga dapat mempengaruhi nyeri haid, apabila status gizi baik maka pada saat menstruasi remaja tidak akan mengalami keluhan seperti nyeri haid atau dismenore. Status gizi dikatakan baik apabila nutrisi yang digunakan oleh tubuh sesuai dengan kebutuhan. ${ }^{9}$ Usia menarche juga mempengaruhi terjadinya nyeri haid, terdapat hubungan antara usia menarche yang terjadi lebih awal dari normal karena alat reproduksi belum siap untuk mengalami perubahan dan masih terjadi penyempitan pada leher rahim, maka akan timbul rasa sakit pada saat mentruasi. ${ }^{10}$ Penelitian ini sejalan dengan penelitian yang dilakukan pada mahasiswi Prodi Ilmu Keolahragaan di 
Universitas Pendidikan Indonesia Kota Bandung yaitu tidak terdapat hubungan antara aktivitas fisik. ${ }^{11}$ Namun berbeda dengan hasil penelitian yang dilakukan di MTs Negeri Surabaya II terhadap 49 siswi kelas VIII, tingkat aktivitas fisik responden berhubungan dengan kejadian dismenorea primer yang dialami $(\mathrm{p}=0,003)$. Dari data penelitian tersebut didapatkanresponden yang memiliki aktivitas fisik yang berat hampir seluruhnya tidak mengalami dismenorea primer. ${ }^{12}$ Dari penelitian ini juga didapatkan bahwa pada beberapa responden yang memiliki tingkat aktivitas fisik berat juga dapat mengalami nyeri haid berat $(6,7 \%)$. Hal ini dapat disebabkan oleh beberapa faktor risiko yang tidak diteliti lebih lanjut oleh peneliti.

\section{KESIMPULAN}

1. Tingkat aktivitas fisik pada santriwati sebagian besar memiliki aktivitas fisik berat $(40,5 \%)$

2. Derajat nyeri haid pada santriwati didominasi oleh nyeri haid ringan $(82,4 \%)$

3. Tidak terdapat hubungan antara aktivitas fisik dengan nyeri haid pada santriwati MAS Ulumuddin Uteunkot-Cunda Kota Lhokseumawe

\section{Saran}

Berdasarkan penelitian yang telah dilakukan, maka peneliti memberi saran sebagai berikut :

1. Bagi santriwati dengan aktifitas fisik ringan dan sedang agar lebih meningkatkan tingkat aktivitas fisik karena selain mengurangi derajat nyeri haid aktivitas fisik yang berat juga baik untuk kesehatan.

2. Bagi santriwati yang mengalami nyeri haid berat dan sedang agar lebih meningkatkan pengetahuan mengenai penatalaksanaan nyeri haid dan mengaplikasikannya dengan harapan nyeri yang dialami dapat berkurang, dan sering mengikuti penyuluhan tentang kesehatan reproduksi agar dapat mengatasi masalah yang berkaitan dengan kesehatan reproduksi secara benar.

3. Bagi pihak yayasan hendaknya bekerja sama dengan instansi terkait atau tenaga kesehatan untuk memberikan informasi mengenai nyeri haid atau kesehatan repsoduksi kepada santriwati

4. Perlu dilakukan penelitian lebih lanjut mengenai faktor lain yang ada hubungan dengan tingkat dismenorea dengan sampel yang lebih banyak. 


\section{DAFTAR PUSTAKA}

1. Kristian., 2010. Dismenorea Primer. Balai Pustaka, Jakarta

2. Prawirohardjo, S., 2008. Ilmu Kandungan. Ed 2, Jakarta :PT Bina Pustaka.

3. Beckmen, et al., 2010. Obstetrics and Ginecology. 6th ed. Philadelpia: LippincottWilliams \& Wilkins.

4. Hendrik, H., 2006. Problema Haid (Tinjauan Syariat Islam dan Medis). Solo:Tiga Serangkai.

5. Ramadani, A. N., 2014. Hubungan Kebiasaan Olahraga dengan kejadian Dismenore pada Siswi di SMPN 2 Demak. Skripsi, STIKES Ngudi Waluyo Ungaran.

6. Kelly, T., 2007. 50 Rahasia Alami Meringankan Sindrom Pramenstruasi. Jakarta : Erlangga.

7. Wiknjosastro, H., 2007. Ilmu Kebidanan. Jakarta: Yayasan Bina Pustaka Sarwono Prawirohardjo.

8. Afrida, S., 2016. Hubungan Dismenorea dengan Presentasi Belajar pada Siswi SMA Negeri 5 Kota Banda Aceh. Skripsi, Universitas Syiah Kuala Banda Aceh

9. Fauzi, A., 2013. Hubungan Indeks Massa Tubuh Dengan Kejadian Dismenore Pada Siswi Mtsn Pitalah Kab. Tanah Datar 2013. Jurnal kesehatan, STIKes Prima Nusantara Kota Bukit Tinggi 10.Paath, E.F., 2007. Gizi dalam Kesehatan Reproduksi. Jakarta : Penerbit Buku Kedokteran EGC

11.Sartika, R.A.D., 2011. Faktor Resiko Obesitas Pada Anak 5-15 Tahun di Indonesia. Universitas Indonesia. [Accesed 29 Juli 2012] Available from : http://journal.ui.ac.id/health/article/viewDownloadInterstitial/796/758

12. Saadiah, S., 2014. Hubungan Aktivitas Fisik dengan Dismenore pada Mahasiswi Program Studi Ilmu Keolahragaan. Skripsi, Universitas Pendidikan Indonesia, Bandung 13. Smeltzer, S. C., \& Bare, B. G., 2005, Buku Ajar Keperawatan Medikal Bedah Brunner dan Suddarth (Ed.8, Vol. 1,2), Alih bahasa oleh Agung Waluyu (dkk), EGC, Jakarta. 